\title{
A CASE OF TUMOR OF THE CEREBELLUM; AUTOPSY.
}

By O. T. Osborne, M.A., M.D.,

PROFESSOR OF MATERIA MEDICA AND THERAPEUTICS AT YALE UNIVERSITY.

On December, 19, I900, Mrs. X., consulted me on account of a chronic cough and dizziness. She was sixty-four years old, had never been very strong and always more or less neurotic. This cough she had had for years, more or less exaggerated at times, with, lately, considerable expectoration. The condition of the lungs was that of a chronic bronchitis, and examinations of the sputum showed no tubercle bacilli. The cough and this bronchitis played no part in the future history of the case.

For four months she had had a great deal of palpitation of the heart and vertigo, these occuring synchronously. With this dizziness there was no ringing in the ears, no disturbance of the eyes, and no nausea. She also had no appetite and was very constipated. The temperature at this examination was $97.4^{\circ}$, and the pulse 96 . She was unable to walk without swaying, and would fall if not assisted. This ataxic condition had been gradually developing during the last four months. There was and had been no headache, pupils reacted normally, patellar reflexes were normal. The urine was found normal with the exception of an increased amount of urates. The diagnosis was made at this time of some disturbance of the circulation in the cerebellum.

She was put to bed, and while strophanthus quieted the heart and the nutrition was maintained, no treatment of the cerebral condition was of any permanent avail. Her dizziness, which during the previous months was especially marked when she first lay down, also often occurred in the middle of the night without any cause or disturburance, or without even a dream; the simple fact of awakening would precipitate an attack. The result of bed-rest was a temporary improvement; the dizziness became less frequent, and consequently the attacks of palpitation were less frequent, as the latter occurred only at the time of the vertigo.

In February of IgoI, that is in two months, the dizziness, which had become infrequent with the first rest treatment, had begun to again increase in frequency. She was utterly unable to sit up without becoming dizzy, and could not turn her head suddenly without an attack of vertigo. In the latter part of this month the dizzy turns became again less frequent, but more severe. She would lie all day with her head turned to the 
right, claiming that she was dizzy if she turned her head to the left. This was without regard to light. The muscles of that side of the neck-were slightly contracted, but the contraction could be easily overcome.

Soon after this the attacks of vertigo began to show epileptoid signs, and during the latter part of the month (February) there were typical epileptic convulsions. Just before this, during the attacks of dizziness, she had begun to complain of double vision, and objects would move and wave before her eyes. One month after she first went to bed she had begun to complain of ringing in the ears during these attacks of vertigo, beginning first, and at first only, in the right ear, but late in February there was ringing in both ears. During these attacks she now began to complain of intense pain in her head referred to the occipital region and described by her as of a "tearing apart sensation" with the sensation of "saw-teeth pricking."

When the epileptic attacks began the left arm was the first to move, and the body always turned toward the left side first. Her movements were frantic and repeated. There was more or less spasmodically voluntary clutching and tearing of the hair with both hands, and the expression of the face was that of intense pain and agony. There was no absolute loss of sensibility, as she would be apparently insensible and then immediately complain of the pain in her head. Inhalations of nitrite of amyl stopped these attacks. She would then sleep more or less soundly from a half hour to an hour. Large doses of bromides kept these attacks, at first, from occurring more frequently than every other day, but they soon became of daily occurence, and except for the inhibitory power of the amyl nitrite a status epilepticus would develop, she having repeated attacks during two or three hours with constant head-pain, and requiring several attendants to keep her from clutching her throat and tearing her hair. During these periods of her trouble the reflexes were all exaggerated, and the vision was perfect.

From this time on, i.e., the latter part of February, she gradually failed, the epileptic attacks became more prolonged; they would come on very rapidly and the convulsiye part was more prominent than in ordinary epileptic convulsions. She would thrash around the bed if not held, and as above stated would tear her hair, clutch her throat and throw herself out of bed if not held. She frequently gave sharp cries during these attacks. The eyes were sometimes staring, but from beginning to end there was never any paralytic eye-signs. She gradually ceased to complain of the ringing in the ears.

About March 4, I90I, she became rather stupified and slept a great deal. The bromide was discontinued, as there were 
now no more epileptic attacks. She could be aroused to swallow or to speak, and recognized the people about her. At this time her eyes were carefully examined and no retinitis found, and the optic disks were normal in appearance and normally cupped.

On March 5 she could take no more food, and lay in pretty constant coma, in which she remained until March 8, when she died. During this semi-comatose period when she could be aroused she would sometimes cry because she said she was unable to say what she wanted to say, and would sometimes start to ask me something and once said that she knew what she wanted to ask but was unable to tell me what it was. Previous to this period she had complained of incoördination in that she said she would attempt to turn to one side of the bed and find herself turning to the other side. She would start to take something with her right hand and find herself taking it with her left. Up to the very last day that she lived her pulse was always good, and she died without having had any Cheyne-Stokes respiration.

There was no paralysis of the sphincters. During her last days there was a good deal of superficial venous congestion, so much so that her face was very dark, as were also her extremities.

My diagnosis had been made at the time the epileptic convulsions began of tumor of the cerebellum, more on the right side than on the left, which diagnosis was confirmed by Dr. Francis Bacon.

We were not allowed a general autopsy in this case, but were permitted to open the skull and examine the brain. The autopsy was performed by Professor Charles J. Bartlett. We found the brain normal except that the right lobe of the cerebellum was distinctly larger and firmer than the left on account of a tumor within it. An examination under the microscope showed this tumor to be a glioma. This growth was sufficient in size to give the pressure symptoms which the case presented. I inferred that the tumor was on the right side, because the ringing of the ears began on that side, and the cortical irritation from the pressure caused the convulsions to begin in the left arm. I expected to find a considerable amount of fluid in the third ventricle. We did find some fluid, but perhaps not more than the normal amount. 